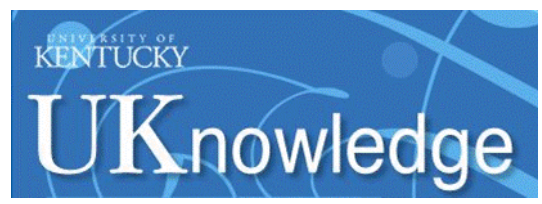

University of Kentucky

UKnowledge

3-1-2017

\title{
Oral Cannabidiol Does Not Produce a Signal for Abuse Liability in Frequent Marijuana Smokers
}

\author{
Shanna Babalonis \\ University of Kentucky, babalonis@uky.edu \\ Margaret Haney \\ Columbia University \\ Robert J. Malcolm \\ Medical University of South Carolina \\ Michelle R. Lofwall \\ University of Kentucky, michelle.lofwall@uky.edu \\ Victoria R. Votaw \\ McLean Hospital
}

See next page for additional authors

Follow this and additional works at: https://uknowledge.uky.edu/behavsci_facpub

Part of the Behavior and Behavior Mechanisms Commons, Chemicals and Drugs Commons, and the Substance Abuse and Addiction Commons

Right click to open a feedback form in a new tab to let us know how this document benefits you.

\section{Repository Citation}

Babalonis, Shanna; Haney, Margaret; Malcolm, Robert J.; Lofwall, Michelle R.; Votaw, Victoria R.;

Sparenborg, Steven; and Walsh, Sharon L., "Oral Cannabidiol Does Not Produce a Signal for Abuse Liability in Frequent Marijuana Smokers" (2017). Behavioral Science Faculty Publications. 41.

https://uknowledge.uky.edu/behavsci_facpub/41

This Article is brought to you for free and open access by the Behavioral Science at UKnowledge. It has been accepted for inclusion in Behavioral Science Faculty Publications by an authorized administrator of UKnowledge. For more information, please contact UKnowledge@lsv.uky.edu. 


\section{Oral Cannabidiol Does Not Produce a Signal for Abuse Liability in Frequent Marijuana Smokers}

\section{Digital Object Identifier (DOI)}

https://doi.org/10.1016/j.drugalcdep.2016.11.030

\section{Notes/Citation Information}

Published in Drug and Alcohol Dependence, v. 172, p. 9-13.

(c) 2016 Elsevier Ireland Ltd. All rights reserved.

This manuscript version is made available under the CC-BY-NC-ND 4.0 license

https://creativecommons.org/licenses/by-nc-nd/4.0/.

The document available for download is the author's post-peer-review final draft of the article.

\section{Authors}

Shanna Babalonis, Margaret Haney, Robert J. Malcolm, Michelle R. Lofwall, Victoria R. Votaw, Steven Sparenborg, and Sharon L. Walsh 


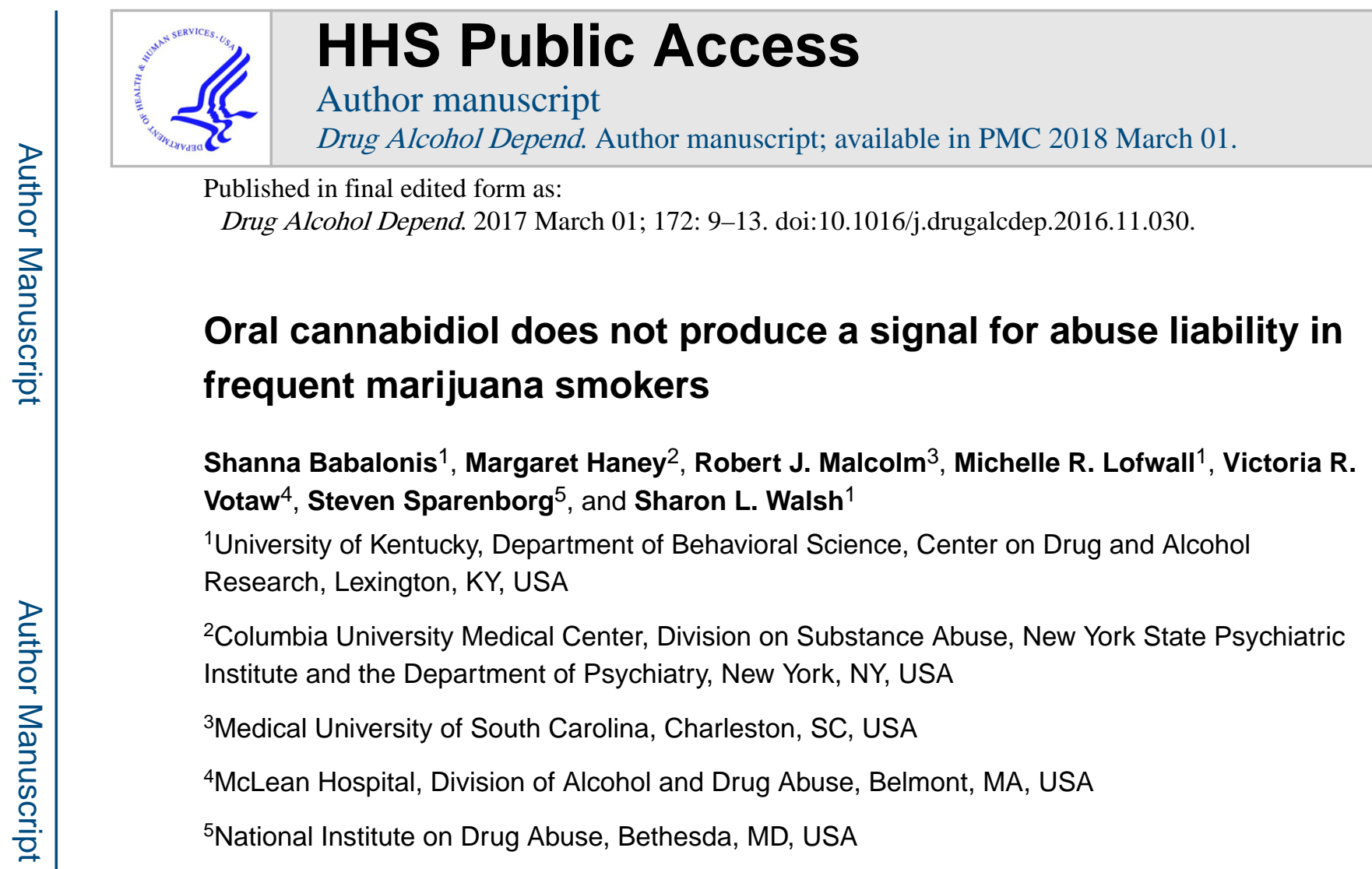

\section{Abstract}

Background-Cannabidiol (CBD) is a naturally occurring constituent of the marijuana plant. In the past few years, there has been great interest in the therapeutic effects of isolated CBD and it is currently being explored for numerous disease conditions (e.g., pain, epilepsy, cancer, various drug dependencies). However, CBD remains a Schedule I drug on the U.S. Controlled Substances Act (CSA). Despite its status, there are no well-controlled data available regarding its abuse liability.

Methods-Healthy, frequent marijuana users $(n=31)$ were enrolled in this within subject, randomized, placebo-controlled, double-blind, multisite study that administered oral cannabidiol $(0,200,400,800 \mathrm{mg})$ alone and in combination with smoked marijuana $(0.01 \%, 5.3-5.8 \%$ THC). Participants received one dose combination across 8 once-weekly outpatient sessions ( $7.5 \mathrm{hrs}$ ). The primary findings on the drug interaction effects were previously reported (Haney et al., 2016). The present study is a secondary analysis of the data to examine the abuse liability profile of oral cannabidiol $(200,400,800 \mathrm{mg})$ in comparison to oral placebo and active smoked marijuana (5.3-5.8\% THC).

Results-Active marijuana reliably produced abuse-related subjective effects (e.g., high) ( $p<.05)$. However, CBD was placebo-like on all measures collected $(p>.05)$.

Conclusions-Overall, CBD did not display any signals of abuse liability at the doses tested and these data may help inform U.S. regulatory decisions regarding CBD schedule on the CSA.

\section{Keywords}

Cannabidiol; CBD; abuse liability; smoked marijuana; human

Corresponding Author: Shanna Babalonis, Ph.D., University of Kentucky College of Medicine, Department of Behavioral Science, Center on Drug and Alcohol Research, 845 Angliana Avenue, Lexington, KY 40508, babalonis@uky.edu, (859) 257-1881. 


\section{Introduction}

Cannabidiol (CBD) and delta-9-tetrahydracannabinol (THC) are two of the dozens of naturally occurring chemicals present in the marijuana plant (e.g., cannabinoids). The concentration of cannabinoids in marijuana varies considerably depending on the strain and plant breeding techniques. For example, confiscated marijuana in the United States and Australia over the past decade has contained minimal concentrations of CBD (CBD: $0.14-$ 0.17\%) (Mehmedic et al., 2010; Swift et al., 2013); however, strains with high concentrations of both THC and CBD (4.5 - 9.3\% CBD) are emerging (Freeman et al., 2014).

Although the mechanism of action of THC has been well documented, the action of CBD on the cannabinoid receptor system is unclear. There is little to no direct activity at $\mathrm{CB}_{1}$ or $\mathrm{CB}_{2}$ receptors (Pertwee, 2010); however, there are data suggesting that CBD may increase endocannabinoid tone by inhibiting fatty acid amide hydrolase (FAAH), an enzyme that degrades the endogenous cannabinoid, anandamide (Bisogno et al., 2001; de Petrocellis et al., 2011). Outside of the cannabinoid system, CBD modulates glycine, adenosine, $\mathrm{TRPV}_{1}$, GPR55, and acts as a 5HT $1 \mathrm{~A}$ agonist (Pertwee et al., 2008; 2010). CBD has also been demonstrated to have antioxidant, anti-inflammatory, neuroprotectant and analgesic effects in preclinical models (Hampson et al., 1998; Maione et al., 2011).

Clinically, CBD is available in several countries (e.g., Israel, England) for therapeutic use and is available on the international market (e.g., Canada, Spain) as a combination product of equal concentrations of CBD and THC (Sative ${ }^{\circledR}$ ) for the treatment of multiple sclerosis spasticity. There are also several single entity CBD products (e.g., Epidiolex ${ }^{\circledR}$, Arvisol ${ }^{\circledR}$ ) in development and under investigation in clinical trials for several disease conditions (e.g., epilepsy, schizophrenia, diabetes, drug dependence); some of these trials have issued reports on the safety of CBD, but data on the efficacy of these products are not yet available. There are also unregulated, non-pharmaceutical products, such as strains of high-CBD marijuana processed to produce oil, that are being used to treat various illnesses - these preparations have not been studied in clinical trials for safety or efficacy and their chemical constituents are largely unknown (with some products containing little to no CBD [FDA Warning Letter, 2015]). One U.S. trial is underway to examine the genetic differences between patients with Dravet syndrome (i.e., intractable epilepsy) who are responders and non-responders to nonpharmaceutical CBD oil (NCT02229032).

Despite the significant interest and increasing use of these products, there are no wellcontrolled published studies that have examined the abuse liability of CBD. Several studies have administered oral doses ( $\$ 600 \mathrm{mg}$ ) of CBD to healthy participants with little to no marijuana use histories and have reported minimal side effects (Bergamaschi et al., 2011; Bhattacharyya et al., 2010; Cunha et al., 1980; Hollister, 1973; Karniol et al., 1974; Zuardi et al., 1993). Oral CBD has been tested in clinical populations (Huntington's disease, epilepsy patients) at much higher cumulative doses (e.g., $1280 \mathrm{mg} / \mathrm{day} ; 50 \mathrm{mg} / \mathrm{kg} / \mathrm{day}$ ) with reports of somnolence, decreased appetite/weight loss, diarrhea and increased seizure in a small subset of epilepsy patients (Consroe et al., 1991; Devinsky et al., 2016; Tzadok et al., 2016). Despite the frequent statements in the media and the scientific literature that CBD is 
void of psychoactive effects, this has never been formally assessed - no studies have completed an abuse liability assessment, enrolled the population of interest (marijuana users) or compared CBD effects to a cannabinoid agent with known abuse liability, such as smoked marijuana, as a positive control.

The current study is a secondary analysis of a trial that examined a wide range of oral CBD doses alone and in combination with smoked marijuana and reported that CBD does not alter the subjective, physiological or reinforcing effects of marijuana (see Haney et al. (2016) for detailed methods). The current analyses focus on the abuse liability of a range of oral CBD doses (up to $800 \mathrm{mg}$ ) compared to oral placebo (negative control) and smoked marijuana (positive control) in a sample of heavy marijuana smokers.

\section{Methods}

\subsection{Participants}

Participants were healthy marijuana smokers who completed in-person screening evaluations that included medical history, physical exam, psychiatric assessments, urinalysis, blood chemistry, and 12-lead ECG. Inclusion criteria included self-report of smoking marijuana at least 4 times per week over the past 4 weeks (half of a joint equivalent on each occasion) and an observed THC-positive urine sample. Exclusion criteria included physiological drug dependence requiring medical care (benzodiazepine, alcohol dependence), pregnancy, and serious medical (e.g., diabetes) or psychiatric (e.g., suicidality) problems (see Haney et al., 2016 for full inclusion/exclusion criteria).

\subsection{Drugs}

The study was conducted under an Investigational Drug Application from the Food and Drug Administration $(113,221)$. Oral CBD doses (pure synthetic (-)-CBD, STI Pharmaceuticals, Essex, England; packaged by Eminent Services Corp., Frederick, Maryland; size 00 capsules) were prepared in blinded packaging by the investigational pharmacy at each site. Marijuana cigarettes (inactive: $0.01 \%$ THC, $0.001 \%$ CBD; active: $5.3 \%-5.8 \%$ THC, $0.01 \%$ CBD) were provided by Research Triangle Institute (RTI).

\subsection{Study Design}

This was a three-site, 8-week randomized, within-subject, double blind, placebo-controlled outpatient study conducted at Columbia University, the Medical University of South Carolina and the University of Kentucky. Each participant completed a total of 8 sessions (7.5 hrs) and received one dose combination of oral CBD $(0,200,400,800 \mathrm{mg})$ and smoked marijuana (0.01, 5.3\%-5.8\% THC) during each session. There was a minimum of 1-week washout between sessions to preclude potential CBD carry-over effects.

This study was approved by the Institutional Review Boards at each university and was conducted in accordance with the Helsinki guidelines for ethical research. All participants provided sober, written informed consent prior to study participation and were paid for their participation. 


\subsection{Physiological Assessments}

Heart rate and blood pressure were collected prior to (baseline) and at regular intervals after CBD administration $(0.5,1,1.4,1.75,2,2.5,3,3.5,4,4.7,5.2,5.7,6.67 \mathrm{hrs}$ - designed to capture the time-action effects of both oral CBD and smoked marijuana).

\subsection{Performance Measures}

Two performance measures, a Digit Symbol Substitution Task (DSST) and a Continuous Performance Task (CPT) were assessed. The DSST is a psychomotor task that assesses speed and accuracy of pattern recognition (3 minute task) and the CPT measures sustained selective attention (5 minute task).

\subsection{Participant-Rated Measures}

Visual analog measures were collected before and at regular intervals after drug administration. Participants rated their responses on a $100 \mathrm{~mm}$ line, anchored with "not at all" (0 mm) to "extremely" (100 mm). Measures included ratings of marijuana drug effects (e.g., street value, drug liking) and a 44-item mood inventory (e.g., high, good drug effects, sedated, alert, hunger), with selected measures having demonstrated sensitivity to cannabinoid agonists (Haney et al., 2004, Lile et al., 2010).

\subsection{Statistical Analysis}

All measures were initially analyzed as raw time course data using a three-factor repeated measures model (marijuana dose, CBD dose, time). Peak/trough scores were analyzed using a one-factor model (dose). Tukey's post-hoc tests examined the time course of the drug effects, individual doses compared to oral placebo, and differences between the comparator dose conditions (e.g., active marijuana/placebo CBD condition compared to cannabidiol [0, 200, 400, $800 \mathrm{mg}] /$ inactive marijuana conditions). All models were conducted with Proc Mixed in SAS 9.3 (Cary, NC) with significance at $\mathrm{p}<0.05$.

\section{Results}

A total of 31 participants completed the study across the three study sites: 14 women, 17 men; mean age ( \pm SEM) was $29.1 \pm 1.7$ years (range: 19 - 49 years). Participants reported smoking marijuana $6.5 \pm 0.2$ days per week and lifetime regular use of $9.3 \pm 1.2$ years (range: $0.5-29$ years); 18 participants were cigarette smokers, 13 were non-smokers. CBD was well tolerated and there were no serious adverse events related to the study medications.

Figure 1 presents peak ratings of the VAS items "I feel high" and "I feel a good drug effect" and a marijuana street value assessment across the five test conditions. In each of the VAS measures displayed (first two panels), active marijuana produced increases in ratings ( $p<$. 05 ), with peak ratings ranging from $52-56$ (out of a maximum of 100) across the measures. In contrast, the active doses of CBD produced minimal effects that were comparable to those of the placebo/inactive marijuana condition (ratings in the range of $11-18)(p>0.05)$.

Placebo CBD and all active doses of CBD produced lower ratings than the active marijuana condition ( $p<0.05$; Table 1). Similar results were obtained for several other measures of drug effect, including ratings of sedated and mellow, with active marijuana increasing ratings

Drug Alcohol Depend. Author manuscript; available in PMC 2018 March 01. 
while CBD doses were placebo-like ( $p<0.05$; see Table 1 ). The far right panel of Figure 1 displays street value estimates, with similar results - the active marijuana dose produced peak street value estimates of $\$ 7.50(p<0.05)$, while active CBD doses $(\$ 3.21-\$ 4.09)$ and the placebo/inactive marijuana condition (\$3.33) produced comparable ratings $(p>0.05)$.

Neither active marijuana nor any dose of active CBD changed performance on the DSST or CPT ( $p>.05)$.

Active marijuana produced increases in peak heart rate ( $p<.05$; Table 1), while CBD was placebo-like on heart rate and blood pressure measures ( $p>.05)$.

Overall, across all the multitude of measures collected, there were no significant effects of CBD detected on peak or time course outcomes $(p>.05)$.

\section{Discussion}

This study enrolled healthy frequent marijuana users and explored the relative abuse liability of a wide dose range of oral CBD in comparison to placebo ( $0.01 \%$ THC) and smoked marijuana (5.3\%-5.8\% THC). Active smoked marijuana reliably produced increases in measures of abuse liability, including ratings of high, like drug effect, drug strength, willing to take again, and mellow. These findings are consistent with a large number of studies that have administered similar doses to marijuana smokers and reported increases in abuserelated subjective measures (e.g., Cooper et al., 2009; 2010; Hart et al., 2002).

The physiological, behavioral and abuse-related subjective effects of a wide range of doses of CBD (200, 400, $800 \mathrm{mg}$ ) were also assessed. In contrast to smoked marijuana, CBD did not produce increases in any subjective ratings of drug effect (relative to placebo $\mathrm{CBD}$ ). Specifically, CBD was placebo-like on all measures collected, including street value estimates and ratings of high, feeling good drug effect, desire to take again, sedated and mellow (Table 1). This lack of detectable effects does not appear to be due to a low dose range or poor bioavailability. The dose range tested is higher than the doses tested (i.e., 600 $\mathrm{mg}$ ) in a study that reported some attenuation of the psychotropic effects of THC (Bhattacharyya et al., 2010). Also, the highest dose tested ( $800 \mathrm{mg}$ dose) appears to be the highest acute oral dose administered to healthy participants (although cumulative daily doses in clinical populations can exceed $1500 \mathrm{mg} /$ day). We previously reported (Haney et al., 2016) that the $800 \mathrm{mg}$ dose was readily absorbed and produced increases in plasma concentrations after administration $\left(\mathrm{C}_{\max }=77.9 \pm 25 \mathrm{ng} / \mathrm{mL}, \mathrm{T}_{\max }=180\right.$ minutes $)$. Overall, these data indicate that CBD, even at very high doses, does not produce any detectable effects in a sample of marijuana smokers and does not display signals of abuse liability.

The ratings of the inactive marijuana/placebo CBD condition for the VAS and street value assessment were slightly elevated (e.g., approximately 10-20/100 on VAS; approximately $\$ 3$ street value), indicating a small placebo response. These placebo ratings were similar to those observed after active CBD dose administration $(p>.05)$. These ratings may be due to the placebo marijuana (designed to smell and taste similar to active marijuana) that was administered with each of these oral doses. Other studies have reported a similar placebo response in marijuana smokers (Cooper and Haney, 2009; Hart et al., 2002). 
This study enrolled heavy marijuana smokers, as they have experience with cannabinoids, and are the appropriate population to test both the efficacy and abuse liability of new cannabinoid medications. However, it is possible that this population was tolerant to the cannabinoid effects produced by CBD and may not be sensitive even to the high dose of CBD tested. It is possible that a higher dose may be necessary to produce measurable effects in this population. Although this is possible, it is unlikely due to the relatively low CBD levels present in many marijuana strains in the U.S. and abroad $(<0.2 \%$ CBD) (ElSohly et al., 2014; Swift et al., 2013). In addition, the subset of participants $(n=8)$ who completed a pharmacokinetic assessment all had circulating CBD levels that were below the limit of quantification $(<0.25 \mathrm{ng} / \mathrm{mL})$ in their plasma prior to CBD administration (Haney et al., 2016), similar to other studies of frequent marijuana smokers (Desrosiers et al., 2014). THC cross-tolerance may also be unlikely because of the unique pharmacological profile of CBD. Although CBD appears to inhibit FAAH and increase anandamide availability, it is an atypical cannabinoid that has action at multiple receptor systems, including $5 \mathrm{HT}_{1 \mathrm{~A}}$, glycine $a_{1}, a_{3}, T_{R P V}$, and GPR55. CBD also appears to be an allosteric modulator of mu- and delta-opioid receptors, voltage-gated sodium channels and inhibit cyclooxygenase (COX) (Kathmann et al., 2006; Patel et al., 2008; for review see Pertwee, 2008). Further, previous studies have administered CBD to normal healthy participants with little to no marijuana use history and have reported very mild or no changes in subjective ratings. Two studies have reported mild anxiolytic effects of 300 and $600 \mathrm{mg}$ CBD (Bergamaschi et al., 2011; Zuardi et al., 1993) when administered prior to an experimental anxiety task. However, other studies have reported no changes in any subjective effects, qualitative self reports or assessments after administration of acute oral ([15, 30, $60 \mathrm{mg}$ ] Karniol et al., 1974; [20-100 mg], Hollister, 1973; [600 mg] Bhattacharyya et al., 2010), chronic oral ([3 mg/kg/day for up to 30 days] Cunha et al., 1980), smoked (150 $\mu \mathrm{g} / \mathrm{kg}$, Dalton et al., 1976), or intravenous ([5-30 mg] Hollister, 1973) CBD doses.

Overall, there is substantial interest in the potential therapeutic effects of CBD, and it is being explored for the treatment of diverse disease conditions (over 25 conditions under investigation, as listed on clinicaltrials.gov). CBD products are available in several countries; however, CBD is currently classified as a Schedule I drug in the United States, which is defined as 1) an agent with high potential for abuse, 2) no currently accepted medical use, and 3) lack of accepted safety information (U.S. Controlled Substances Act, 21 U.S.C. §812). This study addresses the first criterion, as the data indicate that CBD has low potential for abuse; however, it currently remains unclear if CBD is safe for long-term use or clinically useful for the treatment of any of the disease conditions currently under investigation. However, this study may help inform U.S. regulatory decisions if CBD shows medicinal promise in clinical trials.

\section{Acknowledgments}

Funding: Grants from the National Institute on Drug Abuse (DA009236, U10DA013727, U10DA13732) and the National Center for Research Resources and National Center for Advancing of Translational Sciences (UL1TR000117-04 [UK CTSA]; KL2TR000116-04) provided support for this research. 


\section{References}

Bergamaschi MM, Queiroz RH, Chagas MH, de Oliveira DC, De Martinis BS, Kapczinski F, Quevedo J, Roesler R, Schroder N, Nardi AE, Martin-Santos R, Hallak JE, Zuardi AW, Crippa JA. Cannabidiol reduces the anxiety induced by simulated public speaking in treatment-naive social phobia patients. Neuropsychopharmacology. 2011; 36:1219-1226. [PubMed: 21307846]

Bhattacharyya S, Morrison PD, Fusar-Poli P, Martin-Santos R, Borgwardt S, Winton-Brown T, Nosarti C, CM OC, Seal M, Allen P, Mehta MA, Stone JM, Tunstall N, Giampietro V, Kapur S, Murray RM, Zuardi AW, Crippa JA, Atakan Z, McGuire PK. Opposite effects of delta-9tetrahydrocannabinol and cannabidiol on human brain function and psychopathology. Neuropsychopharmacology. 2010; 35:764-774. [PubMed: 19924114]

Bisogno T, Hanus L, De Petrocellis L, Tchilibon S, Ponde DE, Brandi I, Moriello AS, Davis JB, Mechoulam R, Di Marzo V. Molecular targets for cannabidiol and its synthetic analogues: effect on vanilloid VR1 receptors and on the cellular uptake and enzymatic hydrolysis of anandamide. $\mathrm{Br} \mathbf{J}$ Pharmacol. 2001; 134:845-852. [PubMed: 11606325]

Consroe P, Laguna J, Allender J, Snider S, Stern L, Sandyk R, Kennedy K, Schram K. Controlled clinical trial of cannabidiol in Huntington's disease. Pharmacol Biochem Behav. 1991; 40:701-708. [PubMed: 1839644]

Cooper ZD, Haney M. Comparison of subjective, pharmacokinetic, and physiological effects of marijuana smoked as joints and blunts. Drug Alcohol Depend. 2009; 103:107-113. [PubMed: 19443132]

Cooper ZD, Haney M. Opioid antagonism enhances marijuana's effects in heavy marijuana smokers. Psychopharmacology (Berl). 2010; 211:141-148. [PubMed: 20490465]

Cunha JM, Carlini EA, Pereira AE, Ramos OL, Pimentel C, Gagliardi R, Sanvito WL, Lander N, Mechoulam R. Chronic administration of cannabidiol to healthy volunteers and epileptic patients. Pharmacology. 1980; 21:175-185. [PubMed: 7413719]

Dalton WS, Martz R, Lemberger L, Rodda BE, Forney RB. Influence of cannabidiol on delta-9tetrahydrocannabinol effects. Clin Pharmacol Ther. 1976; 19:300-309. [PubMed: 770048]

de Petrocellis L, Ligresti A, Moriello AS, Allara M, Bisogno T, Petrosino S, Stott CG, Di Marzo V. Effects of cannabinoids and cannabinoid-enriched Cannabis extracts on TRP channels and endocannabinoid metabolic enzymes. Br J Pharmacol. 2011; 163:1479-1494. [PubMed: 21175579]

Desrosiers NA, Himes SK, Scheidweiler KB, Concheiro-Guisan M, Gorelick DA, Huestis MA. Phase I and II cannabinoid disposition in blood and plasma of occasional and frequent smokers following controlled smoked cannabis. Clin Chem. 2014; 60:631-643. [PubMed: 24563491]

Devinsky O, Marsh E, Friedman D, Thiele E, Laux L, Sullivan J, Miller I, Flamini R, Wilfong A, Filloux F, Wong M, Tilton N, Bruno P, Bluvstein J, Hedlund J, Kamens R, Maclean J, Nangia S, Singhal NS, Wilson CA, Patel A, Cilio MR. Cannabidiol in patients with treatment-resistant epilepsy: an open-label interventional trial. Lancet Neurol. 2016; 15:270-278. [PubMed: 26724101]

ElSohly MA. Potency Monitoring Program, National Institute on Drug Abuse, Quarterly Report 126. 2014

Freeman TP, Morgan CJ, Hindocha C, Schafer G, Das RK, Curran HV. Just say 'know': how do cannabinoid concentrations influence users' estimates of cannabis potency and the amount they roll in joints? Addiction. 2014; 109:1686-1694. [PubMed: 24894801]

Hampson AJ, Grimaldi M, Axelrod J, Wink D. Cannabidiol and (-)Delta9-tetrahydrocannabinol are neuroprotective antioxidants. Proc Natl Acad Sci U S A. 1998; 95:8268-8273. [PubMed: 9653176]

Haney M, Hart CL, Vosburg SK, Nasser J, Bennett A, Zubaran C, Foltin RW. Marijuana withdrawal in humans: effects of oral THC or divalproex. Neuropsychopharmacology. 2004; 29:158-170. [PubMed: 14560320]

Haney M, Malcolm RJ, Babalonis S, Nuzzo PA, Cooper ZD, Bedi G, Gray KM, McRae-Clark A, Lofwall MR, Sparenborg S, Walsh SL. Oral Cannabidiol does not Alter the Subjective, Reinforcing or Cardiovascular Effects of Smoked Cannabis. Neuropsychopharmacology. 2016; 41:1974-1982. [PubMed: 26708108] 
Hart CL, Ward AS, Haney M, Comer SD, Foltin RW, Fischman MW. Comparison of smoked marijuana and oral Delta(9)-tetrahydrocannabinol in humans. Psychopharmacology (Berl). 2002; 164:407-415. [PubMed: 12457271]

Hollister LE. Cannabidiol and cannabinol in man. Experientia. 1973; 29:825-826. [PubMed: 4724713]

Karniol IG, Shirakawa I, Kasinski N, Pfeferman A, Carlini EA. Cannabidiol interferes with the effects of delta 9 - tetrahydrocannabinol in man. Eur J Pharmacol. 1974; 28:172-177. [PubMed: 4609777]

Kathmann M, Flau K, Redmer A, Trankle C, Schlicker E. Cannabidiol is an allosteric modulator at mu- and delta-opioid receptors. Naunyn Schmiedebergs Arch Pharmacol. 2006; 372:354-361. [PubMed: 16489449]

Lile JA, Kelly TH, Hays LR. Substitution profile of the cannabinoid agonist nabilone in human subjects discriminating delta9-tetrahydrocannabinol. Clin Neuropharmacol. 2010; 33:235-242. [PubMed: 20838217]

Maione S, Piscitelli F, Gatta L, Vita D, De Petrocellis L, Palazzo E, de Novellis V, Di Marzo V. Nonpsychoactive cannabinoids modulate the descending pathway of antinociception in anaesthetized rats through several mechanisms of action. Br J Pharmacol. 2011; 162:584-596. [PubMed: 20942863]

Mehmedic Z, Chandra S, Slade D, Denham H, Foster S, Patel AS, Ross SA, Khan IA, ElSohly MA. Potency trends of Delta9-THC and other cannabinoids in confiscated cannabis preparations from 1993 to 2008. J Forensic Sci. 2010; 55:1209-1217. [PubMed: 20487147]

Patel RR, Barbosa C, Brustovetsky T, Brustovetsky N, Cummins TR. Aberrant epilepsy-associated mutant Nav1.6 sodium channel activity can be targeted with cannabidiol. Brain. 2016; 139:21642181. [PubMed: 27267376]

Pertwee RG. The diverse CB1 and CB2 receptor pharmacology of three plant cannabinoids: delta9tetrahydrocannabinol, cannabidiol and delta9-tetrahydrocannabivarin. Br J Pharmacol. 2008; 153:199-215. [PubMed: 17828291]

Pertwee RG. Receptors and channels targeted by synthetic cannabinoid receptor agonists and antagonists. Curr Med Chem. 2010; 17:1360-1381. [PubMed: 20166927]

Swift W, Wong A, Li KM, Arnold JC, McGregor IS. Analysis of cannabis seizures in NSW, Australia: cannabis potency and cannabinoid profile. PLoS One. 2013; 8:e70052. [PubMed: 23894589]

Tzadok M, Uliel-Siboni S, Linder I, Kramer U, Epstein O, Menascy S, Nissenkorn A, Yosef OB, Hyman E, Granot D, Dor M. CBD-enriched medical cannabis for intractable pediatric epilepsy: the current Israeli experience. Seizure. 2016; 35:41-44. [PubMed: 26800377]

United States Controlled Substances Act Title 21, Subchapter I, Part B, §812. http:// www.deadiversion.usdoj.gov/21 cfr/21usc/812.htm

United States Food and Drug Administration. Warning letters and test results for cannabidiol-related products. 2015. www.fda.gov/NewsEvents/PublicHealthFocus/ucm435591.htm

Zuardi AW, Cosme RA, Graeff FG, Guimaraes FS. Effects of ipsapirone and cannabidiol on human experimental anxiety. J Psychopharmacol. 1993; 7:82-88. [PubMed: 22290374] 

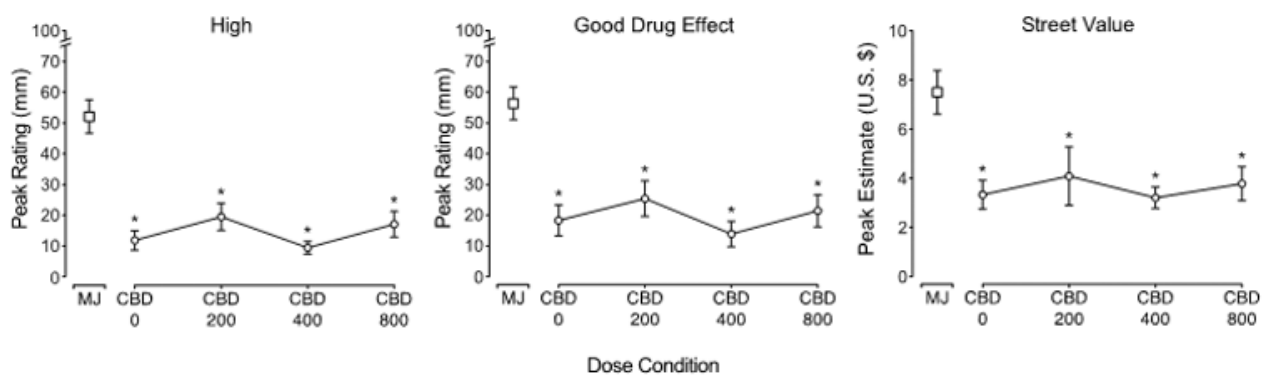

Figure 1.

Peak ratings of the visual analog items "I feel high" (left panel) and "I feel a good drug effect" (middle panel) and estimates from a marijuana street value assessment (right panel) presented as a function of dose condition $(n=31, \pm$ SEM). Peak effect analyses detected a main effect of active marijuana (5.3-5.8\% THC) on each measure. Tukey's post-hoc tests indicated that 1 ) active CBD doses were not significantly different from placebo CBD ( $p$ >. $05)$ and 2) active marijuana condition was significantly different from each of the CBD dose conditions $(0,200,400,800 \mathrm{mg}$, collected under inactive marijuana [0.01\% THC]

conditions), as indicated by the asterisk ( $p<.05)$. The abbreviations on the graphs are as follows: $\mathrm{MJ}=$ active marijuana/placebo $\mathrm{CBD}, \mathrm{CBD} 0=0 \mathrm{mg} \mathrm{CBD} /$ placebo marijuana, $\mathrm{CBD}$ $200=200 \mathrm{mg} \mathrm{CBD} /$ placebo marijuana, $\mathrm{CBD} 400=400 \mathrm{mg} \mathrm{CBD} /$ placebo marijuana, $\mathrm{CBD}$ $800=800 \mathrm{mg} \mathrm{CBD} /$ placebo marijuana. 


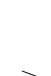<smiles>[CH]1[CH]CC1</smiles>

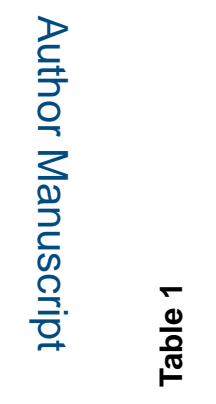

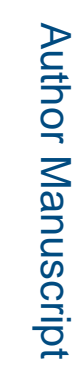

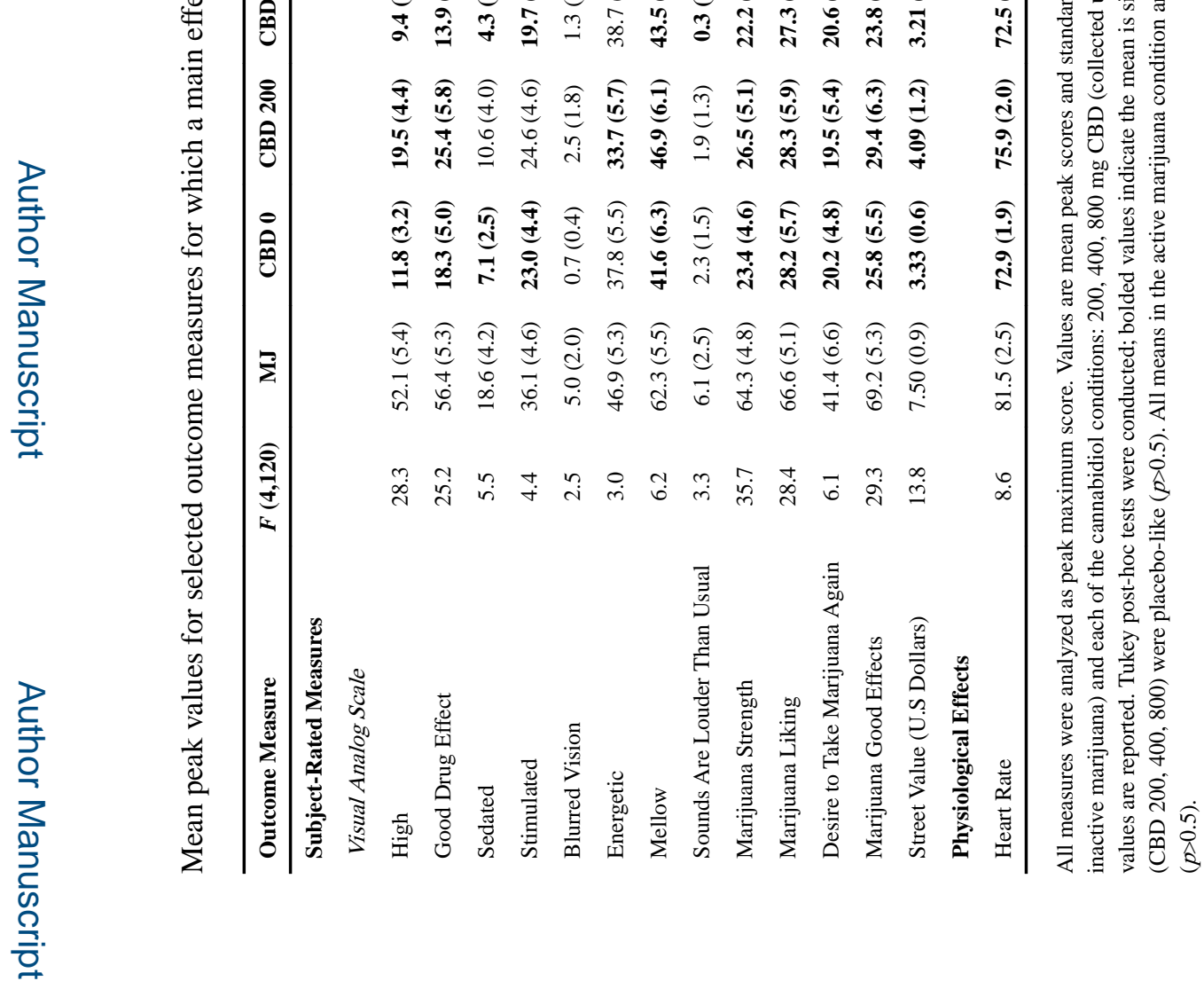

Drug Alcohol Depend. Author manuscript; available in PMC 2018 March 01. 